\title{
Inovações tecnológicas na indústria de móveis: uma avaliação a partir da concentração produtiva de Bento Gonçalves (RS) ${ }^{*}$
}

\author{
Pascoal José Marion Filho \\ Universidade Federal de Santa Maria (UFSM) \\ Cláudia Maria Sonaglio \\ Universidade Estadual do Mato Grosso do Sul (UEMS) e Universidade Federal de Viçosa (UFV)
}

\begin{abstract}
RESUMO
O artigo avalia a adoção de inovações tecnológicas na indústria de móveis retilíneos residenciais de Bento Gonçalves, a principal aglomeração produtiva do Rio Grande do Sul e uma das mais importantes do Brasil. Faz-se uma análise descritiva dos dados obtidos por meio de questionários enviados às empresas, e conclui-se que as inovaçôes mais importantes para a indústria são: de produto, a inclusão de produtos novos para a empresa, mas já existentes no mercado, e alterações no desenho/estilo dos móveis; de processo, mudanças tecnológicas parciais em processos já adotados e a adoção de processos já existentes no setor; e organizacionais, a implementação de novas técnicas de gestão e mudanças na estrutura organizacional. PALAVRAS-ChaVE | inovaçôes tecnológicas; indústria de móveis; móveis.

Códigos JEL | O31; O32; O33.

Os autores agradecem as sugestões apresentadas pelos pareceristas anônimos da RBI, pela dedicação e seriedade no exame do trabalho. As contribuições foram valiosas e ajudaram a melhorar o artigo. As incorreções remanescentes são de inteira responsabilidade dos autores
\end{abstract}


Pascoal José Marion Filho, Cláudia Maria Sonaglio

\title{
Technological innovations in the furniture industry: an evaluation from the productive concentration at Bento Gonçalves (RS)
}

\begin{abstract}
This article makes an evaluation of the technological innovations in the home rectilinear furniture industry at Bento Gonçalves, the main productive agglomeration in Rio Grande do Sul State and one of the most important in Brazil. A descriptive analysis is made using the data obtained trough a questionnaire sent to the industries offices; it concludes that the most important innovations to the industry are: of product, the inclusion of new products to the factory but already present in the market; alterations in the design/style of the furniture; of process, partial technological changes in already existing processes and the adoption of processes that already exist in the sector; and organizational, the implementation of new management techniques and changes in the organizational structure.
\end{abstract}

KEYWORDS | technological innovations; furniture industry; furniture.

JEL-CODES $\quad$ O31; O32; O33.

\section{Introdução}

A eficiência no uso de tecnologias de produto, processo e gestão está diretamente relacionada à competitividade de empresas, cadeias produtivas, regiōes e nações. $\mathrm{O}$ novo paradigma competitivo da chamada "economia do conhecimento" enfatiza a necessidade de as empresas deterem elevada capacidade de aprendizado, para que o conhecimento codificado e amplamente difundido pelo uso de tecnologias de informação seja aplicado ao processo produtivo (CASSIOLATO, 1999).

A simples aquisição de tecnologias não é suficiente para garantir às empresas vantagem competitiva. O processo de geração de inovação contempla um horizonte mais amplo, envolvendo difusão, absorção e aperfeiçoamento de tecnologias para a aplicação na atividade produtiva. Desse modo, as empresas devem possuir com- 
petências para transformar as tecnologias e aplicá-las ao processo. Essas adaptações, somadas ao conhecimento tácito (saber fazer), implicam um processo cumulativo e irreversível que transforma as formas de produção, alterando a dinâmica competitiva.

Diante de tal situação, as empresas passaram a adotar novas formas de gestão do trabalho, gerando e implementando inovações com a preocupação de se ajustarem às exigências mundiais. Para isso, recorrem a estratégias colaborativas como forma de adquirir habilidades que ainda não possuem (BARQUEIRO, 2001).

A ação conjunta das empresas de uma localidade onde predomina um setor produtivo específico, como é o caso do moveleiro em Bento Gonçalves, gera vantagens em termos de acesso facilitado a trabalhadores qualificados (dada a concentração local de mão de obra especializada), a fornecedores de matériasprimas e a serviços correlatos à atividade principal, além da troca de informações entre os agentes, o que contribui para criar um ambiente propício a inovaçōes (MARSHALL, 1985).

Nos últimos anos, aproveitando a ampliação dos mercados, os fabricantes de móveis do Rio Grande do Sul desenvolveram a capacidade de produção e aperfeiçoaram a qualidade dos seus produtos, adotando tecnologias avançadas, matérias-primas sofisticadas e realizando adaptaçôes no design. Esse esforço teve como objetivos manter a indústria competitiva e atender a consumidores de países europeus, especialmente do Reino Unido, e dos Estados Unidos, o que permitiu o aumento das exportações do Brasil de US\$ 40 milhões, em 1990, para US\$1,02 bilhão, em 2005 (ABIMÓVEL, 2005). No ranking brasileiro das exportações de móveis, o Estado ocupou o segundo lugar, sendo responsável por 26,67\% delas.

Polo industrial com significativa inserção no mercado externo, em 2005, Bento Gonçalves respondia por $28,24 \%$ das exportações e por $38,46 \%$ da produção de móveis do Estado (SINDMÓVEIS, 2006). Como a inovação é um importante fator de competitividade, objetiva-se neste estudo avaliar a adoção de inovações tecnológicas na indústria de móveis retilíneos residenciais de Bento Gonçalves, a principal aglomeração produtiva do Rio Grande do Sul.

O artigo organiza-se em cinco seçóes, sendo esta introdução a primeira delas. A segunda seção contempla a fundamentação teórica do estudo e aborda a temática da inovação e da proximidade local. Na sequência, faz-se referência ao método utilizado na pesquisa e, na quarta seção, analisa-se a adoção de inovações tecnológicas na indústria moveleira. Por fim, apresentam-se as conclusōes da pesquisa. 


\section{Fundamentação teórica}

As ações conjuntas dos agentes na busca de novas tecnologias e de novas combinaçôes de uso podem gerar conhecimento. A partir do compartilhamento desse conhecimento científico e tecnológico, codificado ou tácito, selecionado pelo paradigma tecnológico vigente, somado ao uso e desenvolvimento de capacidades específicas de aplicação desse conhecimento, chega-se às novas tecnologias, que podem ser públicas (de livre acesso) ou privadas (protegidas por patentes, por lei, etc.) (DOSI, 1988).

Na tentativa de definir inovação tecnológica, Dosi (1988) afirma que esta é caracterizada como a busca, descoberta, experimentação, desenvolvimento, imitação e adoção de novos produtos, processos e novas técnicas organizacionais, sendo genericamente categorizada em dois tipos: inovação radical e inovação incremental.

Entende-se por inovação radical a introdução de um novo produto, processo ou formas organizacionais da produção, que pode causar uma ruptura estrutural com o padrão tecnológico vigente até então, originando novas indústrias, setores e mercados. Servem de exemplos de ruptura a invenção do motor a vapor no século XVIII, o desenvolvimento da microeletrônica nos anos 1950 (LEMOS, 1999) e, mais recentemente, a fibra ótica, que possibilitou a rápida difusão de informações. Essas inovaçōes, ao se disseminarem, provocam a necessidade de gerar outras inovações, ou seja, tornam necessária a geração de inovações complementares, a criação de infraestrutura adequada, a quebra de resistência dos empresários e consumidores, mudanças na legislação e aprendizado na produção e uso das novas tecnologias (TIGRE, 2005). As melhorias nos produtos, nos processos ou nas organização da produção são classificadas como inovaçóes incrementais no âmbito das empresas e não alteram a estrutura industrial.

O estudo da inovação propriamente dita inicia-se com Schumpeter e a obra Teoria do Desenvolvimento Econômico, de 1912. O autor considera a ação de inovar como criadora de processos de ruptura no sistema econômico, afetando o equilíbrio do fluxo circular. Esse processo de ruptura (introdução da inovação) é provocado pelo empreendedor, que detém a habilidade de ser o primeiro a introduzir novas combinaçôes de meios produtivos, transformando assim o fluxo circular estabelecido.

Assim sendo, para Schumpeter (1982), a inovação é representada pelas novas combinações de produção descontinuadas, sendo um processo absolutamente revolucionário na condição de desenvolvimento econômico, substituindo assim a tradicional forma de competição (competição de preços). 
Segundo Schumpeter (1982, p 47), existe uma distinção importante entre crescimento e desenvolvimento econômico. $\mathrm{O}$ autor considera o primeiro um processo contínuo e gradual, e o segundo, um fenômeno de "mudança espontânea e descontínua nos canais de fluxo, perturbação do equilíbrio, que altera e desloca para sempre o estado de equilíbrio previamente existente". Portanto, este último é um fenômeno instável que não pode ocorrer no conjunto do espaço, mas em determinadas concentraçôes, desenvolvendo alguns setores em detrimento de outros.

É inegável a importância atribuída às inovações no processo competitivo atual. Porém, o exato significado de "inovaçôes" ainda não está definido, como advertem Cassiolato, Vargas e Britto (2005, p. 512). A partir de 1960, estudos empíricos dos pesquisadores da escola evolucionária (Freeman, Rosenberg, Nelson e Winter) permitiram a melhor compreensão do termo, abandonando a ideia de que inovaçôes se limitam a processos de descoberta de novos princípios científicos ou tecnológicos, e assumindo uma característica de aprendizado não-linear, segundo o qual as empresas buscam alternativas por meio de processos experimentais de aprendizado para enfrentar momentos de mudança nas condiçôes econômicas e tecnológicas.

Nesse sentido, o processo de inovação passou a ser entendido como path-dependent (dependente da trajetória), específico do local conformado institucionalmente, como afirmam Cassiolato, Vargas e Britto (2005, p. 513): "a inovação é cada vez mais entendida como sendo um processo que resulta de complexas interações em nível local, nacional e mundial entre indivíduos, firmas e outras organizaçôes voltadas à busca de novos conhecimentos". O entendimento da inovação como variável pathdependent, na abordagem neo-schumpeteriana, é explicado pelo caráter cumulativo e irreversível do processo inovativo, bem como pelas condições de incerteza sob as quais se dá o processo decisório (KUPFER, 1996).

O Modelo Sistêmico de Inovação (MSI) busca ampliar a compreensão do processo de inovação, contemplando a necessidade de abordar a influência simultânea dos fatores organizacionais, institucionais e econômicos, com o objetivo de responder ao questionamento sobre os motivos que levam algumas regiôes a ter desenvolvimento tecnológico superior a outras. Viotti (2003, p. 60), ao apresentar o modelo MSI, chama a atenção para o fato de as empresas não inovarem de maneira isolada, e sim por meio de redes de interações com outras empresas e instituições públicas e privadas, nos moldes dos ensinamentos da Teoria Institucional. Essas interaçōes contemplam também as influências da economia nacional e internacional, o sistema normativo e um conjunto de outras instituições. 
Segundo Roese (2000), a discussão em torno das alternativas diante da globalização colocou em evidência o conceito de Sistemas Nacionais de Inovação (SNI), desenvolvido para explicar os diferentes desempenhos dos países em relação às inovações tecnológicas. A valorização do esforço local em busca de capacitação para a produção de inovações constitui um desencadear de relações interativas que propiciam o uso de um novo conhecimento economicamente viável. Admitindo o processo de inovação nos moldes evolucionários, adota-se como pressuposto que as diferenças na experiência histórica, na linguagem e na cultura, características de diferentes localidades, irão se transformar em idiossincrasias nacionais, regionais ou locais, delimitando o grau de acumulação de conhecimento e capacitações, que resultarão da interação dinâmica dos elementos (RÉVILLION, 2004), não sendo possível comparar dois ou mais sistemas de inovação na busca de definir a melhor trajetória potencial a ser seguida.

Porém, nas economias em desenvolvimento, a inovação, que está no centro da análise do modelo sistêmico, é rara e em muitos casos inexistente, pois os processos de mudança técnica estão limitados à absorção de inovações geradas em outras economias, sendo pequenos os esforços de adaptação e aperfeiçoamento que resultam em inovações incrementais. Nesse sentido, o Modelo de Aprendizado Tecnológico proposto por Viotti (1997) contempla essas duas formas básicas de inovação predominantes nas economias em desenvolvimento. $\mathrm{O}$ autor enfatiza também que o entendimento das diferentes trajetórias de mudanças técnicas das economias desenvolvidas e em vias de desenvolvimento é fundamental para compreender as razóes do crescimento e do desenvolvimento desigual das regióes.

As economias em desenvolvimento, ao ingressarem na produção de larga escala, produzem bens que não são novos para o mercado e enfrentam barreiras estruturais na disputa de mercado. Ou seja, desenvolvem processos de aprendizado tecnológico de dois tipos: aprendizado passivo, em que o país ou a empresa limita-se a absorver essencialmente a capacitação tecnológica de produção e faz esforços mínimos para aprender a utilizá-la; e o aprendizado ativo, em que, além de absorver a capacitação tecnológica, a empresa ou nação demanda recursos para adquirir domínio sobre a capacitação, e assim gerar inovaçōes incrementais a partir de esforços deliberados.

Os conceitos de SNI e cooperação tecnológica buscam explicar o processo de inovação interempresas, contemplando o ambiente institucional e as relações entre os agentes do mercado. A discussão desses modelos fornece alguns fatores que contribuem para a análise desta pesquisa. Ao compreender a essência do modelo SNI, extrai-se a fundamentação para a importância destinada às relaçôes institucionais e 
entre as organizações, contexto em que as ações colaborativas constituem alternativas para as empresas inovarem, agregando competências e habilidades que ainda não possuem. Por sua vez, a contribuição do modelo de aprendizado tecnológico contempla os esforços despendidos na inovação pelas economias de industrialização tardia, como no caso brasileiro.

A abertura da economia brasileira facilitou o acesso às comodidades tecnológicas e ampliou a capacidade de escolha e qualidade no consumo. Buscar maneiras de fomentar o progresso econômico, promover a expansão e o crescimento das empresas já instaladas e propiciar o surgimento de novas empresas continuam sendo o grande desafio. A questão não se limita a analisar se as empresas têm ou não potencial de crescimento, mas inclui verificar em que condiçōes ele ocorre. É nesse contexto, segundo Begnis, Pedrozo e Estivalete (2005), que se passa a perceber a competição sob a ótica das ações de cooperação.

Souza, Mazzali e Bacic (1997) destacam que "a cooperação" é um fator cada vez mais percebido como elemento central na formulação das estratégias competitivas das empresas, tanto no que se refere à superação das desvantagens da "empresa individual" quanto à busca de sinergias interorganizacionais. Cândido e Abreu (2000) apresentam três tipos básicos de vínculos de cooperação entre as organizaçôes:

- vínculos verticais - a montante (fornecedores e subcontratados) e a jusante (consumidores e clientes);

- vínculos horizontais - produtores do mesmo nível, envolvendo ou não instituições de apoio e fomento à atividade empresarial;

- vínculos multilaterais - atuação de instituições de apoio à atividade empresarial da região.

A ideia de que se ganha na formação de aglomerações setoriais em determinado espaço geográfico foi introduzida na economia industrial por Alfred Marshall, na obra Principles of economics, de 1890. Marshall destacou as economias que "frequentemente são asseguradas pela concentração de várias pequenas empresas, com características similares e em determinada localidade". O autor denomina esses ganhos de "economias externas", visando definir por que e como o fator locacional importa, e por que e como pequenas empresas podem ser eficientes e competitivas nos mercados. As localidades foram denominadas "indústria localizada" ou "distritos industriais" (MARSHALL, 1985, p. 231).

Segundo Marshall (1985), as vantagens econômicas (as externalidades positivas), que podem ser obtidas por empresas que pertencem a uma localidade onde 
predomina um setor produtivo específico, decorrem do fácil acesso a trabalhadores qualificados (pela concentração local de mão de obra especializada), a fornecedores de matérias-primas e a serviços correlatos à atividade principal, o que contribui para criar um ambiente propício a inovações.

Entretanto, a simples proximidade local não é suficiente para explicar o desenvolvimento dos arranjos produtivos locais. Nesse sentido, segundo Cândido e Abreu (2000, p. 4), a eficiência coletiva ${ }^{1}$ por meio da concentração de empresas numa mesma localidade pode ser obtida de três formas:

- polos - definidos como uma concentração setorial e geográfica de empresas;

- distrito industrial- caracterizado como um agrupamento de empresas, geralmente de pequeno porte, que agrega as vantagens dos polos à existência de formas implícitas e explícitas de cooperação entre os agentes econômicos locais, proporcionando condiçôes à atividade inovativa;

- redes de empresas - a atuação em rede reserva a particularidade de que o aprendizado mútuo e a inovação coletiva podem ocorrer mesmo quando não existem grandes agrupamentos de empresas, pois a atuação em rede não está condicionada a uma mesma localidade.

Vínculos mais estreitos com compradores, fornecedores e outras instituiçôes trazem benefícios à eficiência e também à velocidade das melhorias e das inovações. De acordo com Porter (1999, p. 221), a localização passa a ser foco da nova abordagem da competição, pois afeta a vantagem competitiva através da produtividade. Com a disponibilidade e abundância dos recursos, o diferencial competitivo ocorrerá por meio da utilização destes, sendo que "a prosperidade depende da produtividade com que os fatores são utilizados e aprimorados numa determinada localidade".

Conceitos baseados na proximidade geográfica, na ativa divisão social do trabalho e na possibilidade de intensa comunicação/cooperação entre os produtores empenham-se em apresentar e justificar os fatores que impulsionam o crescimento a partir de arranjos produtivos locais (APLs) (CASSIOLATO; VARGAS; BRITTO, 2005). No interior dos APLs, os processos informais de aprendizado envolvem a concretização de um pool de informações e conhecimentos que são compartilhados entre seus componentes, demandando a montagem de códigos de linguagem e

1 O conceito de eficiência coletiva foi apresentado por Schmitz (1997). Para o autor, produtores que atuam próximos uns dos outros e fazem a mesma coisa ou coisas semelhantes constituem um cluster. No entanto, menciona que tal concentração geográfica e setorial em si traz poucos benefícios para os mesmos, mas é reconhecidamente um fator facilitador importantíssimo, quando não uma condição necessária, para vários desenvolvimentos subsequentes que podem ou não ocorrer (SCHMITZ, 1997, p. 169). 
canais de comunicação, no intuito de viabilizar esta transferência de maneira eficaz (BRITO, 2004). Assim, são criadas condições mais favoráveis à difusão de inovações tecnológicas e organizacionais entre as empresas que compõem o arranjo (aglomerações). A intensa densidade dos fluxos de informação no âmbito das aglomerações produtivas é um fator de competitividade, sendo importante considerar não apenas o tipo de informação que circula no interior do arranjo (informação mercadológica, tecnológica, relacionada a serviços técnicos, etc.), como também a sua complexidade.

Saber identificar e selecionar as oportunidades nesse mix de conhecimento exige das empresas a formação de competências específicas por meio de um processo de aprendizado contínuo. Segundo Tether (2003), as empresas que inovam são dotadas de rotinas e processos sistemáticos focalizados nas habilidades de aprender e adaptar. Essas empresas são comprometidas com a prática de melhorias que possam culminar em novos produtos ou novos processos. Nesse sentido, Tether (2003, p.10) menciona que as empresas que são inovadoras "tendem a ter um padrão instruído e estável de atividade coletiva pela qual a organização gera e modifica sistematicamente suas rotinas operacionais em busca de melhor efetividade". Esse padrão é denominado capacidades dinâmicas e, segundo Coriat e Dosi (2002), tais capacidades constituem as experiências que habilitam as organizações para executar diferentes tipos de atividades, envolvem atividades organizadas e o seu exercício é tipicamente redundante, sendo as rotinas unidades dessa atividade organizada.

Nesse sentido, de acordo com Campos et al. (2004), a firma age como um repositório de conhecimento e o seu crescimento é determinado, por um lado, pelas suas características internas, tais como rotinas e processos de busca e seleção, definindo processos específicos de aprendizagem e as suas competências; por outro lado, pelo ambiente em que a firma está inserida, em relação ao regime tecnológico, à estrutura produtiva, ao padrão de concorrência e ao contexto social. Desse modo, nos termos da abordagem evolucionária, a avaliação da vantagem competitiva e da aptidão estratégica da empresa é entendida como uma função de seus processos, de suas posiçōes e de suas trajetórias (TEECE, 2005).

Portanto, os autores apresentados concordam que a atuação conjunta de um grupo de empresas do mesmo ramo traz benefícios ao desenvolvimento econômico local e à sustentabilidade das empresas. Entende-se ainda que no atual cenário de acelerada mudança tecnológica, a competitividade não é mais baseada unicamente no preço, mas principalmente na construção de competências específicas para a aquisição de conhecimentos e de inovações, pois os ganhos de eficiência dependem da trajetória inovativa. 


\section{Metodologia}

A produção de móveis pode ser em série, com tecnologia mais moderna e concentração de empresas médias e grandes, ou sob medida (encomenda). Segundo Marion Filho (1997), os móveis podem ser classificados a partir da principal matéria-prima utilizada na sua elaboração (móveis de madeira, metal, plástico, estofados, etc.) e do uso (residenciais, escolares, para escritório, loja, auditório, etc.). Os móveis de madeira podem ser torneados (com madeira maciça trabalhada) ou retilíneos (produzidos em série com chapas de madeira: MDF, compensados e aglomerados).

Foram enviados questionários, por via postal, às empresas do segmento de móveis retilíneos residenciais cadastradas no Sindicato das Indústrias do Mobiliário de Bento Gonçalves (Sindmóveis) e na Associação das Indústrias de Móveis do Estado do Rio Grande do Sul (MOVERGS). Também foram realizadas entrevistas estruturadas com os dirigentes das referidas instituiçōes visando qualificar ainda mais o estudo. Assim, a adoção de inovações tecnológicas na aglomeração produtiva de móveis de Bento Gonçalves é avaliada a partir de uma análise descritiva dos dados obtidos por meio desses questionários.

Havia questôes com dados classificativos, mensurados em escala nominal, em que as categorias são mutuamente excludentes, bem como questôes com escala intervalar, do tipo Likert, ${ }^{2}$ além de questôes de múltiplas respostas. Portanto, as análises apresentadas a seguir não totalizam $100 \%$, e sim o porcentual de empresas que adotaram os diferentes tipos de inovação e a respectiva importância atribuída a cada item. No questionário foi incluído um quadro de definiçôes para dar conhecimento do significado das inovaçōes ${ }^{3}$ avaliadas, são elas:

- inovação de produto (bem ou serviço industrial) - é um produto novo para a sua empresa ou para o mercado e cujas características tecnológicas ou uso previsto diferem significativamente de todos os produtos que sua empresa já produziu;

2 A escala intervalar baseada em Likert foi utilizada na tentativa de mensurar as percepções dos empresários em relação à importância atribuída a cada afirmação. Utilizou-se neste estudo uma escala intervalar de quatro pontos: 1 significa que o item não se aplica; 2, que é pouco importante; 3, importante e 4, muito importante para a empresa.

3 As definições de inovações foram obtidas no Sistema de Informações de Arranjos Produtivos Locais (RedeSist), disponíveis em: <www.ie.ufrj.br/redesist>. A RedeSist foi formalizada em 1997, porém, o grupo de pesquisadores que compõem seu núcleo dedica-se ao estudo dos sistemas produtivos e inovativos locais desde 1980 e é responsável pelo início da difusão deste enfoque no Brasil. 
- alteração tecnológica de produto (bem ou serviço industrial) - refere-se a um produto previamente existente cuja performance foi substancialmente aumentada. Um produto complexo que consiste em um número de componentes ou subsistemas que pode ser aperfeiçoado via mudanças parciais de um dos componentes ou subsistemas. Mudanças puramente estéticas ou de estilo não devem ser consideradas;

- inovação de processos de produção - um processo novo para a sua empresa ou para o setor. Ele envolve a introdução de novos métodos, procedimentos, sistemas, máquinas ou equipamentos que diferem substancialmente daqueles previamente utilizados por sua firma, ou seja, os novos métodos e equipamentos incorporados causam mudanças radicais no processo de produção;

- mudança tecnológica nos processos de produção - envolve importantes mudanças tecnológicas parciais em processos previamente adotados, ou seja, as alterações no processo causadas pela incorporação de novos métodos, procedimentos, sistemas, máquinas ou equipamentos são parciais. Pequenas ou rotineiras mudanças nos processos existentes não devem ser consideradas;

- inovação organizacional - contempla a introdução de novas técnicas de gestão, mudanças na estrutura organizacional (terceirização, integração, alteração/substituição em departamentos, etc.), nas práticas e nos conceitos de marketing (marca, etc.) e de comercialização (logística), formação de redes, bem como a implantação de novos métodos de gerenciamento.

Adotou-se o período de 2000 a 2005 como referência de análise. A escolha desse período visa captar as inovaçôes adotadas após a reestruturação da indústria, contemplando os esforços realizados posteriormente à inserção competitiva no mercado, visto que a indústria de móveis, durante a década de 1990, passou por grandes mudanças devido à abertura comercial e ao Plano Real. Neste período houve investimentos significativos destinados à modernização tecnológica e reestruturação das empresas.

Os questionários foram enviados para a totalidade de fabricantes de móveis retilíneos de Bento Gonçalves (95), e 27 (28,4\%) retornaram preenchidos. Tomando como base o número de empregados (Lei 7.256/1984), participaram da análise: 5 microempresas (até 19 empregados), 15 pequenas empresas (de 20 a 99 empregados), 6 médias empresas (de 100 a 499 empregados) e 1 grande empresa (500 ou mais empregados). Os dados da grande empresa foram agregados ao grupo de médias 
empresas, já que na avaliação crítica constatou-se que as respostas eram próximas, fato que não altera os resultados do estudo.

Os dados foram tabulados com o auxilio do software SPSS 10.0. Utiliza-se na análise quantitativa a estatística descritiva (frequência, média, desvio-padrão e coeficiente de variação).

\section{A geração de inovações tecnológicas na indústria de móveis}

A região serrana do Rio Grande do Sul é conhecida como importante produtora de móveis no país e, em 2005, segundo dados do Sindmóveis (2006), Bento Gonçalves se destaca com 9,59\% da produção nacional. O município abriga 370 fábricas de móveis, entre os quais 95 produzem móveis retilíneos residenciais, e se localiza a $130 \mathrm{~km}$ da capital do Estado, Porto Alegre.

O reconhecimento de Bento Gonçalves como a maior aglomeração moveleira do Estado não se limita ao grande número de empresas que atuam no segmento. $\mathrm{O}$ município abriga o mais importante sindicato do setor no Estado (Sindmóveis) e também a instituição representativa dos produtores no plano estadual, a MOVERGS.

Entre as principais ações do Sindmóveis destacam-se a Movelsul Brasil e o Salâo Design. A Movelsul Brasil, realizada em Bento Gonçalves a cada dois anos, é considerada a feira profissional do ramo moveleiro de maior representatividade na América Latina, sendo consolidada como referência nacional e mundial. Paralelamente a essa feira ocorre o Salão Design Movelsul, que atende à crescente exigência de aprimoramento do design de móveis.

A MOVERGS foi criada em 1987 com o objetivo de representar o setor moveleiro gaúcho, visto que a atuação do Sindmóveis limitava-se ao município de Bento Gonçalves. Entre as principais ações da instituição pode-se destacar o Centro Gestor de Inovação Moveleira (CGI), a Feira Internacional de Máquinas, Matérias-Primas e Acessórios para a Indústria Moveleira - (Fimma Brasil) e o Prêmio Inovação.

O CGI tem como objetivo contribuir para a modernização industrial, por meio de inovações técnicas e tecnológicas voltadas às empresas do setor moveleiro, com ênfase na utilização da infraestrutura laboratorial instalada na região. A Fimma Brasilé realizada em Bento Gonçalves desde 1993. Considerada a maior feira da América Latina e a sexta maior feira mundial do setor, permite a difusão das tendências mundiais de produção, além da divulgação das novas tecnologias disponíveis. O Prêmio Inovação visa incentivar as empresas fornecedoras do Estado do Rio Grande do Sul a apresentar novidades e desta forma criar uma cultura de 
lançamento mundial de máquinas, matérias-primas e acessórios no Brasil, tornando o Estado um centro de referência em tecnologia, capacitação e inovação na cadeia produtiva de madeira e móveis.

Além dessas ações, a MOVERGS e o Sindmóveis atuam de forma cooperativa em outras atividades: organizam fóruns de discussão sobre a cadeia produtiva, distribuem prêmios de incentivo à exportação, fazem programas de garantia de crédito e, principalmente, de incentivo à participação em feiras e eventos nacionais e internacionais.

O Sebrae (Unidade Regional de Negócios de Caxias do Sul) também está aliado ao desenvolvimento do setor moveleiro no polo produtivo de Bento Gonçalves. A instituição atua na capacitação do empreendedor e das empresas por meio de ações como: consultorias gerenciais e tecnológicas nas empresas, formação de grupos setoriais focados na busca de alternativas competitivas e na prospeç̧ão de novos mercados nacionais e internacionais. Também participa da realização de feiras e eventos em parceria com a MOVERGS e o Sindmóveis.

Um importante projeto desenvolvido pelo Sebrae no setor moveleiro é o Sebraexport Móveis, em parceria com a MOVERGS e o Sindmóveis, desde 1998, e que tem como objetivo o aumento das exportações de móveis no Estado. O programa é subsidiado pelo governo federal por meio da Agência de Promoção de Exportações - Apex e promove ações de promoção comercial e capacitação de empresas do setor moveleiro para a atuação no mercado externo. $\mathrm{O}$ ingresso no mercado internacional é facilitado por meio de apoio na participação em feiras, organização de missões comerciais, realização de prospecçôes de mercado, organização de rodadas de negócios, apoio temporário a consultorias comerciais e a capacitação de empresas.

A cidade de Bento Gonçalves abriga também importantes instituições que atuam na formação de recursos humanos com a educação tecnológica, destacandose o Senai/Centro Tecnológico do Mobiliário (Cetemo) e a Universidade de Caxias do Sul (UCS).

O Senai/Cetemo desenvolve suas atividades desde 1983, disponibilizando ao mercado profissionais qualificados para a indústria moveleira. Entre suas principais atividades voltadas ao aprimoramento da produção de móveis destacam-se a pesquisa aplicada e a assessoria tecnológica; na área de educação tecnológica, sobressaem os cursos de aprendizagem, treinamento e qualificação.

Em relação à pesquisa aplicada, o Senai/Cetemo trabalha visando à introdução de inovaçôes incrementais, com o desenvolvimento de novos materiais, processos e produtos. Também atua no desenvolvimento do design, na orientação em termos de 
embalagens e normatização para exportações. Disponibiliza laboratórios para testes de novos materiais, maquinários e componentes. A instituição é referência nacional para o setor moveleiro, participando ativamente das ações de desenvolvimento tecnológico. Além disso, é responsável pela normatização do setor, atuando como coordenador da Associação Brasileira de Normas Técnicas (ABNT) (ROESE, 2000).

A UCS - Campus Vale dos Vinhedos oferece o Curso Superior de Tecnologia em Produção Moveleira, projeto implantado em 1994 a partir dos esforços conjuntos do Sindmóveis, da MOVERGS e do Senai/Cetemo.

$\mathrm{Na}$ pesquisa foi evidenciado que as empresas locais fazem parcerias com as instituiçôes mencionadas para desenvolver várias atividades. No período de $2000 \mathrm{a}$ 2005 , o Senai/Cetemo destaca-se no desenvolvimento de novos produtos $(37,5 \%$ das empresas respondentes fizeram parcerias), no desenvolvimento de novos processos $(55,6 \%)$, nos testes e certificações $(48,0 \%)$, no aproveitamento de resíduos industriais $(40,0 \%)$, na caracterização e seleção de matérias-primas (38,9\%), todas as atividades com frequência ocasional, e no treinamento de pessoal $(35,9 \%)$, atividade recorrente. A MOVERGS e o Sindmóveis participam da realização de eventos (38,8\% e 40,8\%, respectivamente), da organização de participação em eventos $(30,8 \%$ e $34,6 \%)$, da promoção de cursos e seminários $(22,2 \%$ e $30,2 \%)$ e do estabelecimento de contatos e troca de informaçôes (29,2\% para ambas). O Sebrae tem relevância na promoção de consórcios de exportação $(45,5 \%)$ e a UCS teve apenas participações marginais nas interações avaliadas.

As vantagens econômicas de localização na concentração produtiva também foram avaliadas na pesquisa. Os fabricantes de móveis reconhecem como as mais importantes a disponibilidade de mão de obra e a infraestrutura, notas médias de 3,74 e 3,63, respectivamente. Considerando que a escala utilizada varia de 1 a 4, os resultados indicam que as empresas percebem essas vantagens como sendo muito importantes. Este fato é corroborado pelo coeficiente de variação, uma vez que a dispersão em relação à média para a disponibilidade de mão de obra foi de 12,0\% e para a infraestrutura disponível, de 13,4\%, mostrando a conformidade das percepções.

No mesmo sentido, destacam-se a disponibilidade de serviços especializados $(3,56)$, a proximidade dos fornecedores de insumos $(3,26)$ e a presença do centro de pesquisa voltado à produção de móveis $(3,11)$. Portanto, os valores indicam que as empresas consideram as externalidades positivas da atuação na região importantes, visto que todos os itens questionados apresentam valores iguais ou superiores a 3,00 na escala utilizada. 
As principais linhas de produtos fabricadas pelas empresas que participaram da pesquisa são: salas, dormitórios, cozinhas, móveis para banheiros e móveis infantis, produzidos para os mercados nacional e internacional. Em relação à atuação no mercado externo, constatou-se que 18 empresas exportam, em média, 40\% da produção.

Por ser uma região com elevada concentração de empresas produtoras de móveis, a prática de subcontratação para a realização de partes do processo produtivo é bem difundida. Entre as respondentes, 63,0\% subcontratam outra empresa para a realização de etapas do processo produtivo.

$\mathrm{Na}$ sequência, apresentam-se as inovações de produtos, de processos e organizacionais das 27 empresas do segmento de móveis retilíneos residenciais que responderam à pesquisa.

\subsection{Inovações de produtos}

Na pesquisa, verificou-se que as empresas adotaram pelo menos um tipo de inovação de produto no período 2000-2005, conforme a Tabela 1.

TABELA 1

Inovações de produtos na indústria de móveis Bento Gonçalves - 2000-2005

\begin{tabular}{lc}
\hline Inovações de produtos & $\begin{array}{r}\text { \% de empresas que } \\
\text { adotaram inovações }\end{array}$ \\
\hline Inovações no desenho/estilo dos produtos & 88,9 \\
Produto novo para a empresa, mas já existente no mercado onde atua & 85,2 \\
Produto novo para o mercado nacional & 66,7 \\
$\begin{array}{l}\text { Inovações pela utilização de novos materiais (matérias-primas e } \\
\text { componentes) } \\
\text { Produto novo para o mercado internacional }\end{array}$ & 57,7 \\
\hline
\end{tabular}

Fonte: Elaborada pelos autores a partir dos dados dos questionários.

Entre as inovações de produtos, destaca-se a relacionada ao desenho/estilo (utilizada em $88,9 \%$ das empresas). Ela pode ser justificada pelo fato de o móvel ter sua competitividade baseada em fatores como a organização da produção e o desenvolvimento de novos produtos. Assim, o design é um fator importante a ser observado pelas empresas. No entanto, cabe ressaltar que o conceito de design não 
contempla apenas alterações no desenho ou estilo dos móveis, mas vários outros aspectos, como a diminuição do uso de insumos, a redução do número de partes e peças envolvidas num determinado produto, etc.

O design tem sido uma constante preocupação na indústria de móveis da região serrana. As diversas instituiçôes que atuam vinculadas à indústria de móveis (Sindmóveis, MOVERGS, Senai/Cetemo e UCS) têm demandado esforços para aprimorar e desenvolver esse quesito, o que pode ter contribuído para os porcentuais apresentados.

Outro fator que contribui para as inovaçôes dos produtos são os programas desenvolvidos com os fornecedores de insumos, especialmente para as empresas de acessórios e componentes. Estas têm sido incentivadas a desenvolver produtos para a venda no mercado externo, o que resulta na melhoria da qualidade do produto vendido internamente, além do acompanhamento das tendências mundiais. As atividades do Senai/Cetemo em Bento Gonçalves, por meio da pesquisa aplicada, também contribuem para as inovaçôes com uso de novos materiais, pois a instituição vem trabalhando para a melhoria contínua dos insumos utilizados na produção moveleira.

A fabricação de produtos novos para a empresa, mas já existentes no mercado, também se destaca entre as inovações ( $85,2 \%$ das empresas). Isso pode ser explicado pelo fato de a indústria de móveis ser tradicional, cujo resultado da produção mostra-se relativamente simples (ROESE, 2003). Assim, as novidades lançadas por uma determinada empresa difundem-se no mercado, e outras empresas, desde que detentoras das tecnologias necessárias, passam a produzi-las. Dessa forma, a difusão dos produtos no mercado caracteriza a geração de spillover, ou seja, a partir do lançamento dos produtos ocorre seu transbordamento (disseminação) para a indústria.

$\mathrm{Na}$ indústria moveleira as tendências de produção são ditadas pelos países líderes, em especial a Itália. Soma-se a essa característica o fato de as grandes empresas do setor serem difusoras de tendências no Brasil, pois ao lançarem novos produtos estes são rapidamente copiados pelas empresas seguidoras. Para as inovadoras, a apropriabilidade por meio de patentes sobre as inovações na indústria de móveis seria uma forma de proteção e incentivo para os investimentos, pois garantiria os "ganhos de monopólio" nos termos schumpeterianos. Porém, essa prática ainda é incipiente, especialmente no Brasil, onde os custos e a demora para a obtenção do registro são apresentados como limitadores, não apenas para o segmento de móveis, mas para o conjunto da indústria. 
As empresas também avaliaram a importância da adoção das inovações de produtos. Entre as mais utilizadas, o desenho/estilo foi considerado muito importante por $48,1 \%$ das empresas e importante para $40,7 \%$. No entanto, o lançamento de produtos novos teve $70,4 \%$ como muito importante e $29,6 \%$ como importante. Estes porcentuais demonstram a preocupação das empresas produtoras de móveis retilíneos residenciais em inovar seus produtos, mesmo que de maneira incremental, a fim de se manterem no mercado de forma competitiva.

A importância atribuída aos tipos de inovações de produtos, segundo o porte das empresas, pode ser visualizada na Tabela 2. Verifica-se que as empresas atribuíram valores muito próximos aos diferentes itens, mesmo tendo tamanhos diferentes, com destaque para as inovaçôes de novos produtos (média de 3,70) e de alteraçōes no desenho/estilo (média de 3,37). Além disso, constata-se que as empresas pequenas e médias privilegiam as inovaçôes de novos produtos, com notas de 3,73 e 3,86, respectivamente.

Assim, diante da escala de importância (de 1 até 4), percebe-se que os grupos de inovaçōes de produtos tendem a valores próximos a 4, ou seja, são muito importantes para as empresas produtoras de móveis retilíneos.

TABELA 2

Importância das inovações de produtos na indústria de móveis Bento Gonçalves - 2000-2005

\begin{tabular}{|c|c|c|c|c|}
\hline Inovações de produtos & $\begin{array}{l}\text { Porte das } \\
\text { empresas }\end{array}$ & $\begin{array}{l}\text { №s } \\
\text { abs. }\end{array}$ & Média & $\begin{array}{l}\text { Desvio- } \\
\text { padrão }\end{array}$ \\
\hline \multirow[t]{4}{*}{ Alteração no desenho/estilo dos produtos } & Total & 27 & 3,37 & 0,69 \\
\hline & Micro & 5 & 3,40 & 0,55 \\
\hline & Pequena & 15 & 3,27 & 0,80 \\
\hline & Média & 7 & 3,57 & 0,53 \\
\hline \multirow[t]{4}{*}{ Alteração de características técnicas } & Total & 27 & 3,15 & 0,60 \\
\hline & Micro & 5 & 2,80 & 0,84 \\
\hline & Pequena & 15 & 3,13 & 0,52 \\
\hline & Média & 7 & 3,43 & 0,53 \\
\hline \multirow[t]{4}{*}{ Novo produto } & Total & 27 & 3,70 & 0,47 \\
\hline & Micro & 5 & 3,40 & 0,55 \\
\hline & Pequena & 15 & 3,73 & 0,46 \\
\hline & Média & 7 & 3,86 & 0,38 \\
\hline
\end{tabular}

Fonte: Elaborada pelos autores a partir dos dados dos questionários.

O coeficiente de variação das inovaçôes de produtos, que representa a variabilidade relativa entre o desvio-padrão e a média, é de 0,204 para as alterações no 
desenho/estilo dos produtos, 0,190 para as alterações nas características técnicas e 0,127 para novos produtos. Estes coeficientes refletem a homogeneidade das respostas, pois a dispersão ficou em torno de $20,0 \%$ para os dois primeiros tipos de inovaçôes e de $12,7 \%$ para as inovaçôes com novos produtos.

\subsection{Inovações de processos}

As inovações de processos caracterizam-se pela introdução de novos métodos, procedimentos, sistemas, máquinas ou equipamentos. São considerados processos novos a introdução de inovações que diferem substancialmente daqueles processos previamente utilizados pela empresa. Por sua vez, as mudanças tecnológicas são alterações parciais em processos adotados anteriormente e se caracterizam como inovaçôes incrementais.

No Brasil, a indústria de móveis passou por importantes inovaçóes nos processos com a modernização de plantas produtivas, especialmente na década de 1990, quando o governo deu incentivos para a importação de máquinas e equipamentos sem similar nacional, a fim de tornar a indústria nacional competitiva. Ressalta-se que é uma característica da indústria moveleira brasileira a importação de tecnologias de produção dos países europeus, especialmente da Itália, onde a indústria de bens de capital mantém intensa interatividade com as empresas produtoras de móveis e, dessa forma, desenvolve máquinas específicas para atender à demanda da indústria.

Nos anos 1990, as empresas da região serrana, em especial as de médio e grande portes, passaram por reestruturações e adotaram equipamentos automatizados, o que aumentou a produtividade e reduziu o número de funcionários, alterando a relação capital/trabalho.

Após esse impulso inicial, mesmo com o incipiente estágio da indústria de bens de capital nacional, as empresas produtoras de móveis continuaram a incorporar novas formas de produção. A proximidade do fornecedor e a realização de feiras internacionais na regiāo (como a Fimma Brasil) proporcionam uma excelente oportunidade para a atualização tecnológica das empresas voltadas à produção de móveis. Soma-se a este fato a atuação das instituições locais voltadas ao desenvolvimento da produção moveleira, as quais, por meio de pesquisas aplicadas, vêm desenvolvendo novos equipamentos e formas de produção. A Tabela 3 apresenta os porcentuais de empresas produtoras de móveis retilíneos residenciais que adotaram inovações de processos no período de 2000 a 2005. 
TABELA 3

Inovações de processos na indústria de móveis Bento Gonçalves - 2000-2005

\begin{tabular}{lc}
\hline Inovações de processos & $\begin{array}{c}\text { \% de empresas que } \\
\text { adotaram inovações }\end{array}$ \\
\hline Mudança tecnológica parcial em processos previamente adotados & 81,5 \\
Processo tecnológico novo para a sua empresa, mas já existente no setor & 77,8 \\
Processo tecnológico novo para o setor de atuação & 40,7 \\
\hline
\end{tabular}

Fonte: Elaborada pelos autores a partir dos dados dos questionários.

Verifica-se que, entre as empresas pesquisadas, $81,5 \%$ realizaram mudanças tecnológicas parciais em processos previamente adotados e $77,8 \%$ introduziram processos tecnológicos novos, mas já existentes no setor. Em relação ao primeiro quesito, observa-se na indústria moveleira o desenvolvimento de maquinário específico para determinadas etapas da produção. Estas inovaçōes incrementais nos processos também podem ser explicadas pela mudança tecnológica ocorrida na década de 1990, visto que este estudo contemplou o período 2000-2005, quando não seria mais possível uma modernização radical, devido ao volume de investimento necessário. Portanto, as inovações de processos adotadas pelas empresas produtoras de móveis retilíneos residenciais tendem a ser incrementais.

A produção de móveis demanda trabalho manual e maquinário específico, fato que leva muitas empresas a desenvolver internamente seus equipamentos e processos de produção. Verificou-se, assim, que $48,1 \%$ das firmas participaram diretamente do desenvolvimento das inovaçôes de processos, internamente ou em parceria com instituições, e que quase 30,0\% das inovações de processos foram desenvolvidas ou adquiridas em Bento Gonçalves, fato explicado por ser uma região especializada na produção de móveis e abrigar quase todos os segmentos da cadeia produtiva.

Em relação à importância atribuída pelas empresas aos tipos de inovação de processo, $51,9 \%$ das que inovam consideram muito importante a incorporação de novos equipamentos na atual planta industrial e $48,1 \%$ definiram como importantes as mudanças na configuração da atual planta industrial.

Em relação aos valores médios atribuídos aos grupos de inovações de processos (Tabela 4), constata-se que a incorporação de novos equipamentos na atual planta industrial apresentou média de 3,33 (muito importante), puxada para cima pelas microempresas, com um coeficiente de variação de 0,249 . Por sua vez, as mudanças 
na configuração da atual planta industrial receberam média de 3,15 (muito importante), com dispersão de $24,7 \%$, consideradas mais importantes pelas maiores empresas.

\section{TABELA 4}

Importância das inovações de processos na indústria de móveis Bento Gonçalves - 2000-2005

\begin{tabular}{l|l|r|r|c}
\hline Inovações de processos & $\begin{array}{l}\text { Porte das } \\
\text { empresas }\end{array}$ & $\begin{array}{c}\text { Nos } \\
\text { abs. }\end{array}$ & Média & $\begin{array}{c}\text { Desvio- } \\
\text { padrão }\end{array}$ \\
\hline $\begin{array}{l}\text { Incorporação de novos equipamentos na atual } \\
\text { planta industrial }\end{array}$ & $\begin{array}{l}\text { Total } \\
\text { Micro }\end{array}$ & $\mathbf{2 7}$ & $\mathbf{3 , 3 3}$ & $\mathbf{0 , 8 3}$ \\
& Pequena & 15 & 3,60 & 0,55 \\
& Média & 7 & 3,20 & 1,01 \\
Mudanças na configuração da atual planta & Total & $\mathbf{2 7}$ & $\mathbf{3 , 4 3}$ & $\mathbf{0 , 7 9}$ \\
industrial & Micro & 5 & 3,20 & 0,45 \\
& Pequena & 15 & 3,13 & 0,92 \\
& Média & 7 & 3,29 & 0,76 \\
\hline
\end{tabular}

Fonte: Elaborada pelos autores a partir dos dados dos questionários.

\subsection{Inovações organizacionais}

Entre as inovações organizacionais destacam-se: a introdução de novas técnicas de gestão; mudanças na estrutura organizacional, que contemplam as terceirizações e a integração vertical, a substituição de setores e/ou departamentos e a formação de redes de cooperação; as mudanças nas práticas e conceitos de marketing, que por sua vez abordam as questôes referentes à marca; as práticas de comercialização, especialmente logística e pontos de venda; e os programas de qualidade. A Tabela 5 apresenta os porcentuais das empresas que adotaram inovaçóes organizacionais no período 2000-2005.

Verifica-se entre os grupos de inovações organizacionais a predominância de empresas que adotaram mudanças na estrutura da organização $(85,2 \%)$ e implementaram novas técnicas de gestão $(81,5 \%)$. Com relação ao primeiro quesito, destacam-se as terceirizaçôes e as substituiçôes ou alterações nos departamentos, consideradas importantes por $48,1 \%$ e $44,4 \%$ das empresas, respectivamente, corroborando a análise sobre subcontratação. 
TABELA 5

Inovações organizacionais na indústria de móveis Bento Gonçalves - 2000-2005

\begin{tabular}{l|c}
\hline Inovações organizacionais & $\begin{array}{c}\text { \% de empresas que } \\
\text { adotaram a inovação }\end{array}$ \\
\hline Implementação de mudanças significativas na estrutura organizacional & 85,2 \\
Implementação de novas técnicas de gestão & 81,5 \\
Mudanças significativas nas práticas de marketing & 66,7 \\
Mudanças significativas nas formas de comercialização & 48,1 \\
Implementação de programas de qualidade & 37,0 \\
\hline Fonte: Elaborada pelos autores a partir dos dados dos questionários.
\end{tabular}

A integração foi citada como uma importante inovação organizacional por aproximadamente $30 \%$ das empresas, em especial as de médio e grande portes, visto a estratégia de agregação de valor que vem sendo implementada na região, com a criação de lojas próprias e atendimento especializado aos clientes. Em relação à produção de matérias-primas, algumas empresas produzem internamente componentes para o acabamento do móvel (puxadores, dobradiças, etc.). Por sua vez, as redes de cooperação foram apontadas por 33,3\% dos respondentes como uma prática que não se aplica na produção de móveis retilíneos residenciais. As demais empresas $(66,7 \%)$ atribuíram pouca importância a esse tipo de inovação organizacional.

Na Tabela 6, observa-se que 37,0\% das empresas produtoras de móveis retilíneos residenciais adotaram programas de qualidade no período 2000-2005. Estas são na sua maioria exportadoras, fato que pode ter sido influenciado pelas exigências do mercado externo em termos de padrōes e especificações.

Em relação às inovaçôes organizacionais, constatou-se que $63,0 \%$ das empresas consideraram importante a introdução de novas técnicas de gestão e 48,1\% definiram como muito importante a alteração nas práticas de comercialização, com um valor médio de 3,25 (ver Tabela 6), apesar de ter sido adotada por menos de $50 \%$ das empresas.

Considerando-se na análise o porte das empresas, verifica-se que as microempresas atribuíram valores médios inferiores aos conferidos pelas de maior porte, com coeficiente de variação superior a $40 \%$. Esse fato pode ser justificado pela necessidade que as empresas de menor porte têm de inovar seus processos e atender com maior flexibilidade às demandas da produção, conforme constatado na Tabela 4, em que as médias de importância atribuídas pelas microempresas às inovações de processos se aproximam de 4, ou seja, estas são muito importantes. 
Em relação aos coeficientes de variação dos tipos de inovações organizacionais, a importância atribuída a programas de qualidade apresenta variabilidade relativa, entre o desvio-padrão e a média, superior a $40 \%$, ou seja, as respostas são pouco homogêneas. As inovaçóes por meio de mudanças nas práticas de comercialização, nas práticas de marketing e na estrutura organizacional exibem dispersão em torno de $30 \%$. No entanto, a introdução de novas técnicas de gestão mostra maior homogeneidade das respostas, com coeficiente de 0,20.

\section{TABELA 6}

Importância das inovações organizacionais na indústria de móveis Bento Gonçalves - 2000-2005

\begin{tabular}{llr|r|c}
\hline Inovações organizacionais & $\begin{array}{l}\text { Porte das } \\
\text { empresas }\end{array}$ & $\begin{array}{r}\text { Nos } \\
\text { abs. }\end{array}$ & Média & $\begin{array}{c}\text { Desvio- } \\
\text { padrão }\end{array}$ \\
\hline Introdução de novas técnicas de gestão & Total & $\mathbf{2 6}$ & $\mathbf{3 , 2 3}$ & $\mathbf{0 , 6 5}$ \\
& Micro & 5 & 2,80 & 1,10 \\
& Pequena & 14 & 3,21 & 0,43 \\
& Média & 7 & 3,57 & 0,53 \\
Mudanças na estrutura organizacional & Total & $\mathbf{2 1}$ & $\mathbf{3 , 1 0}$ & $\mathbf{1 , 0 4}$ \\
& Micro & 3 & 2,33 & 0,84 \\
& Pequena & 11 & 3,09 & 0,52 \\
Alterações nas práticas de marketing & Média & 7 & 3,43 & 0,79 \\
& Total & $\mathbf{2 1}$ & $\mathbf{3 , 2 4}$ & $\mathbf{1 , 0 0}$ \\
Alterações nas práticas de comercialização & Micro & 3 & 2,67 & 1,15 \\
& Pequena & 11 & 3,36 & 0,92 \\
& Média & 7 & 3,29 & 1,11
\end{tabular}

Fonte: Elaborada pelos autores a partir dos dados dos questionários.

A incorporação de inovações não depende apenas dos esforços individuais das empresas, mas também do somatório dos esforços das instituições públicas e privadas e das políticas de incentivo e fomento. Assim, a ação conjunta das empresas produtoras de móveis, dos fornecedores de máquinas, equipamentos e insumos, somada aos esforços das instituiçôes representativas ou de pesquisa e desenvolvimento têm um papel importante na dinâmica do processo. 


\section{Conclusões}

O estudo avalia a adoção de inovações tecnológicas na aglomeração produtiva de móveis de Bento Gonçalves, principal polo moveleiro do Rio Grande do Sul e um dos principais do Brasil.

A atuação das empresas em aglomerações produtivas é tida como um facilitador da difusão e geração de inovaçôes, graças à ação interativa dos agentes e das instituições, em que a proximidade geográfica e a cultura comum permitem a transmissão e troca de conhecimentos. A pesquisa evidencia que as inovaçôes e interações ocorrem no polo moveleiro, e que os agentes compartilham dos fluxos de informaçōes e das açóes colaborativas, formando vínculos horizontais e multilaterais, valorizando o esforço local, o que é reconhecido pelo modelo sistêmico.

As economias externas da concentração produtiva, nos moldes destacados por Marshall, também foram constatadas no estudo, especialmente no que se refere à mão de obra especializada e à infraestrutura. Isso mostra que o fator locacional importa para os produtores e que as externalidades positivas são valorizadas.

No período de 2000 a 2005, as empresas produtoras de móveis retilíneos residenciais de Bento Gonçalves incorporaram inovações organizacionais e de produtos e processos. Entre as inovações de produtos destacam-se as alterações no seu desenho/estilo e a elaboração de produtos novos para a empresa, mas já existentes no mercado (geração de spillover ou transbordamento de tendências), reafirmando a tendência da indústria de móveis de seguir os padrões de lançamentos dos países líderes.

Em relação às inovações de processo, destacam-se as mudanças tecnológicas parciais em processos previamente adotados pela empresa (inovaçōes incrementais), aprendizado ativo, já que na década de 1990 ocorreram inovaçôes radicais pela importação de máquinas, e a adoção de processos já existentes no setor, porém novos para as empresas.

No tocante às inovaçōes organizacionais, as mudanças na estrutura (terceirizações e mudanças nos departamentos) e a implementação de novas técnicas de gestão foram as principais incorporações.

Considerando-se o porte das empresas, as microempresas identificaram como principal inovação a incorporação de novos equipamentos na atual planta industrial (inovação de processo). As pequenas e médias empresas definiram como mais importante o lançamento de novos produtos (inovação de produto). 


\section{Referências bibliográficas}

ABIMÓVEL - Associação Brasileira das Indústrias do Mobiliário. Panorama do setor moveleiro no Brasil. São Paulo, jun. 2005. Disponível em: <http://www.abimovel.org.br>. Acesso em: 12 maio 2006.

AGHION, P.; HOWITT, P.; MAYER-FOULKES, D. The Effect of Financial Development on Convergence: Theory and Evidence. The Quarterly Journal of Economics, v. 120, n. 1, p. 173-222, February 2005.

BARQUEIRO, A.V. Desenvolvimento endógeno em tempos de globalização. Porto Alegre: Fundação de Economia e Estatística, 2001.

BEGNIS, H.S.M.; PEDROZO, E.A.; ESTIVALETE, V.F.B. Cooperação enquanto estratégia segundo diferentes perspectivas teóricas. In: ENCONTRO NACIONAL DE PÓS-GRADUAÇÃO EM ADMINISTRAÇÃO, 29, Brasília. Anais... Brasília, Enanpad, 2005.

BRITO, J. Cooperação e aprendizado em arranjos produtivos locais: em busca de um referencial analítico. Rio de Janeiro, ago. 2004. Disponível em: <http:// www.ie.ufrj.br/ redesist>. Acesso em: 18 jul. 2005.

CAMPOS, R.R. et al. Aprendizagem por interação: pequenas empresas em sistemas produtivos e inovativos locais. Rio de Janeiro, ago. 2004. Disponível em: <http://www.ie.ufrj. br/redesist>. Acesso em: 17 jul. 2005.

CÂNDIDO, G.A.; ABREU, A.F. Os conceitos de redes e as relações interorganizacionais: um estudo exploratório. In: ENCONTRO NACIONAL DE PÓS-GRADUAÇÃO EM ADMINISTRAÇÃO, 24., Florianópolis. Anais... Florianópolis, Anpad, 2000. 1 CD.

CASSIOLATO, J.E. A economia do conhecimento e as novas políticas industriais e tecnológicas. In: LASTRES, H.M.M.; ALBAGLI, S. (Org.). Informação e globalização na era do conhecimento. Rio de Janeiro: Campus, 1999.

CASSIOLATO, J.E.; VARGAS, M.A.; BRITTO, J. N. de P. Arranjos cooperativos e inovação na indústria brasileira. In: DE NEGRI, J.A.; SALERMO, M.S. (Org.). Inovações, padrões tecnológicos e desempenho das firmas industriais brasileiras. Brasília: Ipea, 2005.

CORIAT, B.; DOSI, G. The nature and accumulation of organizational competences/ capabilities. Revista Brasileira de Inovação, v. 1, n. 2, jul./dez. 2002.

DOSI, G. The nature of the innovative process. In: DOSI, G. et al. (Org.). Technical change and economic theory. London: Pinter Publishers, 1988. 
KUPFER, D. Uma abordagem neo-schumpeteriana da competitividade industrial. Ensaios FEE, ano 17 , n. 1, p. 335-72, 1996.

LEMOS, C. Inovação na era do conhecimento. In: LASTRES, H.M.M.; ALBAGLI, S. (Org.). Informação e globalização na era do conhecimento. Rio de Janeiro: Campus, 1999.

MARION FILHO, P. J. A evolução e a organização recente da indústria de móveis nos estados de Santa Catarina e Rio Grande do Sul. Tese (Doutorado em Ciências - Economia Aplicada) - Escola Superior de Agricultura "Luiz Queiroz" - ESALQ, USP, Piracicaba, 1997.

MARSHALL, A. Princípios de economia. São Paulo: Nova Cultural, 1985.

MYTELKA, L.; FARINELLI, F. De aglomerados locais a sistemas de inovação. In: LASTRES, H.M.M.; CASSIOLATO, J.E.; ARROIO, A. (Org.). Conhecimento, sistemas de inovação e desenvolvimento. Rio de Janeiro: Editora UFRJ/Contraponto, 2005.

PORTER, M.E. Competição=on competition: estratégias competitivas essenciais. Rio de Janeiro: Campus, 1999.

RÉVILLION, J.P.P. Análise dos sistemas setoriais de inovação das cadeias produtivas de leite fluido na França e no Brasil. Tese (Doutorado em Agronegócios). Programa de Pós-Graduação em Agronegócios do Centro de Estudos e Pesquisas em Agronegócios da Universidade Federal do Rio Grande do Sul - UFRGS, 2004.

ROESE, M. Política industrial e de C\&T regional: sistemas de inovação regionais? O caso da aglomeração moveleira de Bento Gonçalves/RS. Revista Eletrônica de Administração. v. 6, n. 4, jul./ago. 2000. Disponível em: <http:// www.read.ea.ufrgs.br>. Acesso em: 15 maio 2005.

Problemas globais, respostas locais: a indústria de móveis de madeira no Brasil à luz dos enfoques de cadeias produtivas e sistemas regionais de inovação. Tese (Doutorado em Política Científica e Tecnológica) - Instituto de Geociências - Universidade Estadual de Campinas , Campinas, SP, 2003.

SCHMITZ, H. Eficiência coletiva: caminho de crescimento para a indústria de pequeno porte. Ensaios FEE, Porto Alegre, Fundação de Economia e Estatística Siegfried Emanuel Heuser, v. 18, n. 2, p. 164-200. 1997.

SCHUMPETER, J.A. Teoria do desenvolvimento econômico: uma investigação sobre lucros, capital, crédito, juros e o ciclo econômico. São Paulo: Abril Cultural, 1982. (Os Economistas).

SIEGEL, S. Estatística não-paramétrica para as ciências do comportamento. São Paulo: McGraw-Hill do Brasil, 1975.

SINDMÓVEIS - Sindicato das Indústrias do Mobiliário de Bento Gonçalves. Disponível em: $<$ http://www.sindmoveis.com.br/port/default.asp?page=dados.asp >. Acesso em: 15 maio 2006. 
Pascoal José Marion Filho, Cláudia Maria Sonaglio

SOUZA, M.C.A.F; MAZZALI, L.; BACIC, M.J. Relaçóes de cooperação com grandes empresas: oportunidades e limites para o desenvolvimento de pequenas e médias empresas: reflexōes para o caso do Brasil. Ensaios FEE, Porto Alegre: Fundação de Economia e Estatística Siegfried Emanuel Heuser, v. 18, n. 2, p. 201-234, 1997.

TEECE, D.J. As aptidões das empresas e o desenvolvimento econômico: implicações para as economias de industrialização recente. In: KIM, L.; NELSON, R. (Org.). Tecnologia, aprendizado e inovação: as experiências das economias de industrialização recente. Campinas, SP: Unicamp, 2005.

TETHER, B.S. What is innovation? Approaches to distinguishing new product and processes from existing products and processes. CRIC Working paper, n. 12, ago. 2003.

TIGRE, P. Inovação e teorias da firma em três paradigmas. Modulo 1 - Sociedade do conhecimento - Mestrado Executivo em Inteligência Empresarial. Disponível em: <www.ie.ufrj. br/redesist>. Acesso em: 23 abr. 2005.

VIOTTI, E.B. Fundamentos e evolução dos indicadores de CT\&I. In: VIOTTI, E. B.; MACEDO, M. de M. (Org.). Indicadores de ciência, tecnologia e inovação no Brasil. Campinas: Unicamp, 2003.

. Passive and Active Learning Systems: a Framework to Understand Technical Change in Late Industrializing Economies and Some Evidences from a Comparative Study of Brazil and South Korea. Tese (Doutorado) - The New School for Social Research, Nova York, 1997.

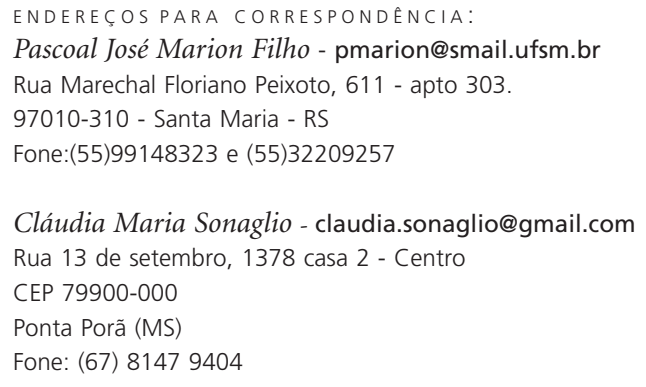

